\title{
An update of the Hong Kong Epilepsy Guideline: consensus statement on the use of antiepileptic drugs in Hong Kong
}

\author{
Jason KY Fong, Eric LY Chan, Howan Leung *, Iris Chan, Richard SK Chang, Gardian CY Fong, \\ Eva LW Fung, Colin HT Lui, Ben BH Fung, TL Poon, Deyond Siu, HT Wong, Eric Yeung, Ada WY Yung, \\ Cannon XL Zhu; Subcommittee on the Consensus Statement of The Hong Kong Epilepsy Society
}

\section{A B S T R A C T}

Objective: New information about antiepileptic drugs has arisen since the publication of the Hong Kong Epilepsy Guideline in 2009. This article set out to fill the knowledge gap between 2007 and 2016 on the use of antiepileptic drugs in Hong Kong.

Participants: Between May 2014 and April 2016, four consensus meetings were held in Hong Kong, where a group comprising 15 professionals (neurologists, paediatricians, neurosurgeons, radiologists, and clinical psychologists) from both public and private sectors aimed to review the best available evidence and update all practising physicians on a range of clinical issues including drug-related matters. All participants were council members of The Hong Kong Epilepsy Society.

Evidence: A literature review of the clinical use of antiepileptic drugs as monotherapy suggested Level A evidence for levetiracetam and Level B evidence for lacosamide. No change in the level of evidence was found for oxcarbazepine (Level A evidence) or pregabalin (undesignated), and no evidence was found for perampanel. A literature review on the clinical use of antiepileptic drugs as adjunctive therapy suggested Level A evidence for both lacosamide and perampanel. No change to the level of evidence was found for levetiracetam (Level A evidence), oxcarbazepine (Level A evidence), or pregabalin (Level A evidence). A literature search on the use of generic antiepileptic drugs suggested Level A evidence for the use of lamotrigine in generic substitution.

Consensus process: Three lead authors of the Subcommittee drafted the manuscript that consisted of two parts-part A: evidence on new antiepileptic drugs, and part B: generic drugs. The recommendations on monotherapy/adjunctive therapy were presented during the meetings. The pros and cons for our health care system of generic substitution were discussed. The recommendations represent the 'general consensus' of the participants in keeping with the evidence found in the literature.

Conclusions: Recommendations for the use of levetiracetam, lacosamide, oxcarbazepine, pregabalin, and perampanel were made. The consensus statements may provide a reference to physicians in their daily practice. Controversy exists over the use of generic products among patients who are currently taking brand medications. In this regard, approvals from prescriber and patient are pivotal. Good communication between doctors and patients is essential, as well as enlisting the assistance of doctors, nurses, and pharmacists, therapeutic blood monitoring if available, and the option of brand antiepileptic drug as a self-financed item. The physical appearance of generic drugs should be considered as it may hamper drug compliance. Support from medical services is recommended. In the longer term, the benefit of flexibility and the options to have a balance between the generic and brand drug market may need to be addressed by institutions and regulatory bodies.

Hong Kong Med J 2017;23:74-88

DOI: 10.12809/hkmj166027

Subcommittee on the Consensus Statement of The Hong Kong Epilepsy Society

1 JKY Fong, FHKCP, FHKAM (Medicine)

${ }^{2}$ ELY Chan, FHKCP, FHKAM (Medicine)

${ }^{3}$ H Leung *, FHKCP, FHKAM (Medicine)

${ }^{4}$ I Chan, PhD

${ }^{5}$ RSK Chang, FHKCP, FHKAM (Medicine)

${ }^{1}$ GCY Fong, FHKCP, FHKAM (Medicine)

${ }^{6}$ ELW Fung, FHKCP, FHKAM (Paediatrics)

CHT Lui, FHKCP, FHKAM (Medicine)

${ }^{8}$ BBH Fung, FHKCP, FHKAM (Medicine)

${ }^{9}$ TL Poon, FCSHK, FHKAM (Surgery)

${ }^{10} \mathrm{D}$ Siu, FHKCR, FHKAM (Radiology)

${ }^{11}$ HT Wong, FCSHK, FHKAM (Surgery)

${ }^{12}$ E Yeung, FHKCP, FHKAM (Medicine)

${ }^{13}$ AWY Yung, FHKCP, FHKAM (Paediatrics)

${ }^{14}$ CXL Zhu, FRCS, FHKAM (Surgery)

Private practice, Hong Kong

Department of Medicine and Geriatrics, Tuen Mun Hospital, Tuen Mun, Hong Kong

Department of Medicine and Therapeutics, Prince of Wales Hospital, Shatin, Hong Kong

${ }^{4}$ Department of Medicine, Queen Elizabeth Hospital, Jordan, Hong Kong ${ }^{5}$ Department of Medicine, Queen Mary Hospital, Pokfulam, Hong Kong

Department of Paediatrics, Prince of Wales Hospital, Shatin, Hong Kong

Department of Medicine, Tseung Kwan O Hospital, Tseung Kwan O, Hong Kong

Department of Medicine, United Christian Hospital, Kwun Tong, Hong Kong

${ }^{9}$ Department of Neurosurgery, Queen Elizabeth Hospital, Jordan, Hong Kong

${ }^{10}$ Department of Radiology, Kwong Wah Hospital, Yaumatei, Hong Kong

${ }^{11}$ Department of Neurosurgery, Kwong Wah Hospital, Yaumatei, Hong Kong

${ }^{12}$ Department of Medicine, Pamela Youde Nethersole Eastern Hospital,

Chai Wan, Hong Kong

${ }^{13}$ Department of Paediatrics, Queen Mary Hospital, Pokfulam, Hong Kong

${ }^{14}$ Department of Surgery, Prince of Wales Hospital, Shatin, Hong Kong

*Corresponding author: howanleung@cuhk.edu.hk 


\section{Introduction}

Epilepsy is a chronic neurological condition that places a high economic burden on patients from childhood to senescence. In Hong Kong alone, more than 70000 patients have seizures as a chronic condition and many more have developed seizures as a result of an acute symptomatic medical condition; both of which may require the use of antiepileptic drugs (AEDs). There are currently 155 registered pharmaceutical products in Hong Kong classed as AEDs and approved by the Department of Health, excluding drugs that are prescribed off-label. The general guiding principles for physicians in the selection of AEDs are derived from evidence-based medicine and the last version of The Hong Kong Epilepsy Guideline already provides ample advice. ${ }^{1}$ As the number of published papers and metaanalysis is fast-growing, The Hong Kong Epilepsy Society (HKES) considers it important to review the best available evidence and to update all practising physicians with regard to their position on a range of clinical issues including drug-related matters. As such, HKES prepared a series of consensus statements to supplement The Hong Kong Epilepsy Guideline of 2009.

Four consensus meetings were convened between May 2014 and April 2016 during which time a group of 15 professionals consisting of neurologists, paediatricians, neurosurgeons, radiologists, and clinical psychologists participated in structured discussions in four major areas: AEDs, status epilepticus, refractory epilepsy, and women and epilepsy. The participants represented both the public and private sectors. They were all council members of HKES. The current paper addresses the topic of AEDs.

In part A of this consensus statement, we have compiled all the papers and studies published in 2007 or later, using the citation index from PubMed, Ovid and Google Scholar, that are concerned with the clinical use of AEDs as either monotherapy or adjunctive therapy. The research papers must be written in English with seizure outcome as their primary endpoint. Only AEDs licensed in Hong Kong after 2001 are included in this review. Studies pertaining to benzodiazepine and intravenous preparations only of any AED were not reviewed, nor were those that focused exclusively on subgroups of patients in which prognosis may be affected by parameters other than drug treatment (eg neurosurgical cohorts).

The research papers were rated as randomised controlled trial, cohort study (including retrospective study), meta-analysis or review, and where possible, graded as class I, II, or III level of evidence, in line with the previous version of The Hong Kong Epilepsy Guideline. ${ }^{1}$ Level A evidence is defined as the availability of one Class I study or more, or meta-

\section{香港腦瘑指引更新：香港使用腦痛藥物的 共識聲明}

方嘉揚、陳樂耀、梁浩雲、陳詠詩、張錫坤、方頌恩、 馮麗華、呂曉東、馮斌熙、潘德立、蕭容媛、黃海東、 楊思偉、楊穎欣、朱献倫；香港腦痭學會共識聲明附屬委員會

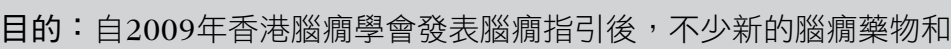
相關資訊陸續出現。本文回顧2007年至2016年之間腦痌藥物的資訊。

參與者：2014年5月至2016年4月期間舉行了四次共識會議。成員由 15位來自公營及私營醫療系統的專業人士組成, 當中包括腦科、兒 科、腦外科和放射科醫生, 以及臨床心理專家。會議旨在討論根據最 佳現有證據, 為業界提供最新腦痭藥物的資訊。所有參與者均為香港 腦癇學會的成員。

證據：單藥治療方面, 開普蘭（levetiracetam）的臨床證據已經達到 循證醫學甲級水平, 拉科酰胺（lacosamide）也達到乙級水平。至於 奥卡西平 (oxcarbazepine) 和普瑞巴林 (pregabalin) 的證據則沒有任 何改變。癲控達膜衣錠（perampanel）還沒有足夠的循証證據。至於 輔助治療的應用方面, 拉科酰胺和癲控達膜衣錠也達到甲級水平。開 普蘭、奥卡西平和普瑞巴林則並沒有改變（它們均達至甲級水平）。 關於學名藥的文獻, 目前拉莫三嗪（lamotrigine）鈉通道阻斷劑的循 証證據已經達到甲級水平

綜述過程：附屬委員會中三位主要成員負責編寫文章, 當中包含兩個 部份：第一部份為新藥的證據, 第二部份則關於學名藥的使用。會議 中發表了有關單藥治療和輔助療法的建議, 亦廣泛討論學名藥的優點 和缺點。專家建議提供整體性的共識, 也大致接納臨床的證據。

結論：專家建議對開普蘭、拉科酰胺、奥卡西平、普瑞巴林和癲控達 膜衣錠的使用提供了指引, 亦可作為醫生臨床的參考。病人從品牌藥 轉服學名藥是一具爭論性的議題。當中處方醫生以及病人的同意至關 重要。我們亦應注意病人與醫生之間的溝通, 醫生、護士和藥劑師的 協助, 血液濃度的幫助（如有），以及自費品牌藥選擇的提供。學名 藥的外型跟品牌藥的差異也可以帶來服藥依從性的問題。醫護人員的 支援也是非常重要的。長遠來説, 可能須要由監管機構解決用藥的靈 活性, 以及學名藥和品牌藥市場之間取得平衡的選擇。

analysis suggesting a similar rating. Level B evidence is defined as the availability of one Class II study or more, or meta-analysis suggesting a similar rating. Level $\mathrm{C}$ evidence is defined as the presence of more than two Class III studies.

In part $B$ of this consensus statement, we have compiled all the studies published in 2007 or later, using the citation index from PubMed, Ovid and Google Scholar, that are related to human studies of generic preparations of AEDs. The same classification of evidence is employed. The analyses in both parts A and B are of particular importance to local health care providers, because Hong Kong has a special health-financing situation in which the majority of patients are treated under the public hospital system. As a result, hospital-based practice 
is likely to influence the standard of care delivered to the majority of chronic epilepsy patients and the health care costs of medical treatment.

\section{Part A: evidence on new antiepileptic drugs}

A total of 95 eligible papers were submitted for the purpose of writing this consensus statement. Articles that focused on zonisamide, eslicarbazepine, and brivaracetam were not reviewed because these agents were not registered with Department of Health at the time of writing. Papers pertaining to topiramate were not reviewed as the drug was registered in Hong Kong before 2001. Papers on retigabine were not reviewed as this drug has currently limited usage in Hong Kong following an alert from the Food and Drug Administration (FDA) of the United States. The remaining drugs of interest were collated based on their indications.

\section{Monotherapy}

\section{Levetiracetam}

Two Class I studies, 10 Class II studies, and 16 Class III studies were found under this indication for levetiracetam (LEV). One Class I study that randomised patients to LEV or carbamazepine found non-inferiority of LEV. ${ }^{2}$ Another Class I study randomised paediatric patients with juvenile absence epilepsy to LEV or placebo and reported a nonsignificant superiority in terms of seizure response. ${ }^{3}$ One Class II study compared LEV with lamotrigine (LTG) and another Class II study compared LEV with carbamazepine or sodium valproate. Both studies demonstrated that LEV was as efficacious as the other standard regimens. ${ }^{4,5}$
The evidence in the paediatric population was generally positive. ${ }^{3,4,6,7}$ At the opposite end of the spectrum, geriatric patients were also shown in a Class II study to benefit from LEV monotherapy. ${ }^{8}$ One Class II study detailed the conversion of treatment in patients with existing partial-onset epilepsy to extended-release LEV monotherapy. ${ }^{9}$ In the Chinese population, one Class III study demonstrated the usefulness of LEV monotherapy. ${ }^{10}$ The overall level of conclusion is supported by an expedited review from the International League Against Epilepsy (ILAE). ${ }^{11}$

Statement 1: The level of evidence for LEV monotherapy reaches Level A.

\section{Oxcarbazepine}

Four Class III studies and one meta-analysis were found under this indication for oxcarbazepine (OXC). Another three Class III studies recruited patients with mixed indications (Table $1^{12-19}$ ). The evidence in the paediatric subgroup suggested that OXC may be useful in children across a range of conditions, from idiopathic to symptomatic and cryptogenic epilepsy. ${ }^{12}$ Of interest, one study that recruited Chinese patients for the purpose of both mono- and adjunctive therapy showed that OXC was as effective as LTG or topiramate. ${ }^{13}$ Oxcarbazepine is already indicated as monotherapy in partial epilepsy. The recommendation for the use of OXC remains unchanged.

Statement 2: The level of evidence for OXC monotherapy remains unchanged (Level A).

\section{Lacosamide}

Lacosamide (LCS) produces slow inactivation of neuronal sodium channels. We found one Class

TABLE I. A review of the use of oxcarbazepine as an antiepileptic drug ${ }^{12-19}$

\begin{tabular}{|c|c|c|}
\hline Study & Class & Study population / outcome \\
\hline \multicolumn{3}{|c|}{ Monotherapy. Level of evidence reached: A. Recommendation: unchanged from The Hong Kong Epilepsy Guideline 2009} \\
\hline Koch and Polman, ${ }^{15} 2009$ & Meta-analysis & CBZ and OXC were similarly effective and well-tolerated \\
\hline Eun et al, ${ }^{16} 2012$ & Class III & Paediatrics \\
\hline Franzoni et al, ${ }^{12} 2009$ & Class III & Paediatrics \\
\hline Franzoni et al, ${ }^{12} 2009$ & Class III & OXC was effective and well-tolerated in paediatric group \\
\hline Dogan et al, ${ }^{17} 2008$ & Class III & Adults, $62.6 \%$ were seizure-free; discontinuation rate: $8 \%$ \\
\hline \multicolumn{3}{|c|}{ Adjunctive therapy. Level of evidence reached: A. Recommendation: unchanged from The Hong Kong Epilepsy Guideline 2009} \\
\hline French et al, ${ }^{14} 2014$ & Class I & Extended-release preparation \\
\hline \multicolumn{3}{|l|}{ Mixed } \\
\hline Kang et al, ${ }^{13} 2012$ & Class III & Adult \\
\hline Lee et al, ${ }^{18} 2010$ & Class III & Adult \\
\hline Seneviratne et al, ${ }^{19} 2008$ & Class III & Adult \\
\hline
\end{tabular}

Abbreviations: CBZ = carbamazepine; $O X C=$ oxcarbazepine 
II study and two Class III studies on the use of LCS monotherapy and two Class III studies with mixed indications (Table $2^{20-45}$ ). One conversion study showed that 425 patients completed LCS maintenance with a favourable safety profile at a nominal dose of $400 \mathrm{mg}$ per day. ${ }^{20}$ In another study, the seizure-free rate was $72.3 \%$ at 1 year and the withdrawal rate was $15 \%{ }^{21}$ In the study by Lattanzi et $\mathrm{al}^{22} 58$ patients were converted from a background single AED to LCS with just over half $(55.2 \%)$ becoming seizure-free. Only $20.8 \%$ of patients reported mild-to-moderate adverse events. The FDA has approved use of LCS as monotherapy in epilepsy since September 2014 and there was a plan to seek its approval for use with the same indication in Europe in 2016.
Statement 3: The level of evidence for LCS monotherapy reaches Level $\mathrm{B}$.

\section{Pregabalin}

Pregabalin (PGB) has binding properties to the alpha-2-delta units of calcium channels. We found one Class I study, one Class II study, and one metaanalysis for PGB under this indication (Table $3^{14,46-57}$ ). Pregabalin was compared with LTG in a study of 330 patients using a double-blind, non-inferiority design with the primary efficacy endpoint being the proportion of patients to achieve seizure freedom for 6 months. In the study, however, PGB was inferior to LTG on both intention-to-treat and perprotocol analyses ${ }^{46}$ In the study by French et al, ${ }^{14}$ conversion from a first or second AED to PGB was

TABLE 2. A review of the use of lacosamide as an antiepileptic drug ${ }^{20-45}$

\begin{tabular}{|c|c|c|}
\hline Study & Class & Study population / outcome \\
\hline \multicolumn{3}{|c|}{ Monotherapy. Level of evidence reached: B. Recommendation: changed from The Hong Kong Epilepsy Guideline 2009} \\
\hline Wechsler et al, ${ }^{20} 2014$ & Class II & Adult \\
\hline Giráldez et al, ${ }^{21} 2015$ & Class III & Adult \\
\hline Lattanzi et al, ${ }^{22} 2015$ & Class III & Adult (conversion) \\
\hline \multicolumn{3}{|c|}{ Adjunctive therapy. Level of evidence reached: A. Recommendation: changed from The Hong Kong Epilepsy Guideline $200 \mathrm{~S}$} \\
\hline Husain et al, ${ }^{23} 2012$ & Class I & Adult \\
\hline Runge et al, ${ }^{24} 2015$ & Class III & Adult \\
\hline Stephen et al, ${ }^{25} 2014$ & Class III & Adult (21.9\% seizure-free and $21.9 \%$ had $>50 \%$ reduction) \\
\hline Pasha et al, ${ }^{26} 2014$ & Class III & Paediatric \\
\hline Rosenfeld et al, ${ }^{27} 2014$ & Class III & Adult (open-label extension) \\
\hline Gulati et $a l,{ }^{28} 2015$ & Class III & Paediatric \\
\hline Rosenow et al, ${ }^{29} 2015$ & Class III & Adult (open-label extension) \\
\hline Geffrey et al, ${ }^{30} 2015$ & Class III & Tuberous sclerosis complex patients \\
\hline Flores et al, ${ }^{31} 2012$ & Class III & Adult (UK epilepsy clinic) \\
\hline Kamel et al, ${ }^{32} 2013$ & Class III & Adult \\
\hline Verrotti et al, ${ }^{33} 2013$ & Class III & Adult and paediatric \\
\hline Toupin et al, ${ }^{34} 2015$ & Class III & Paediatric \\
\hline Zadeh et al, ${ }^{35} 2015$ & Class III & Adult \\
\hline Rastogi and $\mathrm{Ng},{ }^{36} 2012$ & Class III & Paediatric \\
\hline Grosso et al, ${ }^{37} 2014$ & Class III & Paediatric \\
\hline Grosso et al, ${ }^{38} 2014$ & Class III & Lennox-Gastaut syndrome, paediatric (reduction 29\%) \\
\hline Lee et $a l,{ }^{39} 2016$ & Class III & Adjunctive LCS to LEV monotherapy \\
\hline Buck and Goodkin, ${ }^{40} 2012$ & Meta-analysis & Paediatric \\
\hline Paquette et al, ${ }^{41} 2015$ & Meta-analysis & 14 Studies (38\%-41\% achieved $50 \%$ responder rate) \\
\hline Biton et al, ${ }^{42} 2015$ & Meta-analysis & - \\
\hline Sawh et al, ${ }^{43} 2013$ & Meta-analysis & - \\
\hline \multicolumn{3}{|l|}{ Mixed } \\
\hline Yorns et al, ${ }^{44} 2014$ & Class III & Paediatric \\
\hline Novy et al, ${ }^{45} 2013$ & Class III & Adult \\
\hline
\end{tabular}

Abbreviations: $\mathrm{LCS}=$ lacosamide; $\mathrm{LEV}=$ levetiracetam 
undertaken in 125 patients and the results showed Perampanel

that PGB monotherapy was safe and efficacious in partial epilepsy. No recommendation may be given at this stage regarding the use of PGB monotherapy in epilepsy.

Statement 4: The level of evidence for PGB monotherapy remains unchanged (not designated).
No study on the use of perampanel (PER) monotherapy could be found using the current search criteria. Other information pertaining to PER is shown in Table $4 . .^{58-69}$

Statement 5: The level of evidence for PER monotherapy remains unchanged (no recommendation).

TABLE 3. A review of the use of pregabalin as antiepileptic drug ${ }^{14,46-57}$

\begin{tabular}{|c|c|c|}
\hline Study & Class & Study population / outcome \\
\hline \multicolumn{3}{|c|}{ Monotherapy. Level of evidence reached: undesignated. Recommendation: no recommendation at present } \\
\hline Kwan et al, ${ }^{46} 2011$ & Class I & Adult \\
\hline French et al, ${ }^{14} 2014$ & Class II & Historical controlled trial, positive for patients inadequately controlled \\
\hline Zhou et al, ${ }^{49} 2012$ & Meta-analysis & \\
\hline \multicolumn{3}{|c|}{ Adjunctive therapy. Level of evidence reached: A. Recommendation: unchanged from The Hong Kong Epilepsy Guideline $200 \mathrm{~S}$} \\
\hline French et al, ${ }^{14} 2014$ & Class I & Adult, controlled release \\
\hline Zaccara et al, ${ }^{47} 2014^{*}$ & Class $I^{*}$ & Non-inferiority comparison between PGB and LEV \\
\hline Lee et al, ${ }^{48} 2009$ & Class I & Adult \\
\hline Valentin et al, ${ }^{50} 2009$ & Class III & Adult \\
\hline Tsounis et al, ${ }^{51} 2011$ & Class III & Adult \\
\hline Stephen et al,,$^{52} 2011$ & Class III & Adult, high rate of withdrawal \\
\hline Ryvlin et al, ${ }^{53} 2010$ & Class III & Adult \\
\hline Pulman et al, ${ }^{54} 2014$ & Meta-analysis & - \\
\hline Lozsadi et al, ${ }^{55} 2008$ & Meta-analysis & - \\
\hline Gil-Nagel et al, ${ }^{56} 2009$ & Meta-analysis & - \\
\hline Uthman et al, ${ }^{57} 2010$ & Meta-analysis & $30 \%$ Withdrawal rate \\
\hline
\end{tabular}

Abbreviations: $L E V$ = levetiracetam; $P G B=$ pregabalin

* This study differs from other Class I studies in that the comparison arm was an antiepileptic agent rather than placebo

TABLE 4. A review of the use of perampanel as an antiepileptic drug ${ }^{58-69}$

\begin{tabular}{|c|c|c|}
\hline Study & Class & Study population / outcome \\
\hline \multicolumn{3}{|c|}{ Monotherapy. Level of evidence reached: undesignated. Recommendation: no recommendation at present } \\
\hline \multicolumn{3}{|l|}{ No study } \\
\hline \multicolumn{3}{|c|}{ Adjunctive therapy. Level of evidence reached: A. Recommendation: changed from The Hong Kong Epilepsy Guideline 2009} \\
\hline French et al, ${ }^{60} 2012$ (study 304) & Class I & $>12$ Years of age, $50 \%$ responder rate of $64.2 \%$ \\
\hline French et al, ${ }^{59} 2013$ (study 305) & Class I & \\
\hline French et al, ${ }^{58} 2015$ & Class I & Idiopathic generalised epilepsy \\
\hline Krauss et al, ${ }^{61} 2012$ (study 306, 307) & Class I & \\
\hline Juhl and Rubboli, ${ }^{63} 2016$ & Class III & Adult, $50 \%$ responder rate of $27.2 \%$ \\
\hline Brodie and Stephen, ${ }^{64} 2016$ & Class III & Adult, $50 \%$ responder rate of $14.8 \%$ \\
\hline Shah et al, ${ }^{65} 2016$ & Class III & Adult, $50 \%$ responder rate of $57.5 \%$ \\
\hline Kwan et al, ${ }^{62} 2015$ & Pooled results & Enzyme-inducing AED might affect PER \\
\hline Steinhoff et al, ${ }^{66} 2014$ & Class III & Retention rate of $69 \%$ \\
\hline Kramer et al, ${ }^{67} 2014$ & Pooled results & Increasing dose from 8 to $12 \mathrm{mg}$ might provide additional benefits \\
\hline Steinhoff et al, ${ }^{68} 2014$ & Class III & $50 \%$ Responder rate of $46 \%$ \\
\hline Hsu et al, ${ }^{69} 2013$ & Meta-analysis & - \\
\hline
\end{tabular}

Abbreviations: $A E D=$ antiepileptic drug; PER = perampanel 


\section{Adjunctive therapy}

\section{Levetiracetam}

One Class I and two Class III studies were identified using the search criteria. In addition, two Class III studies reported mixed indications and two meta-analyses were published (Table $5^{2-10,13,70-94}$ ). In the only Class I study available for this indication, patients with idiopathic generalised epilepsy were randomised to receive LEV $3000 \mathrm{mg}$ per day or placebo. The results suggested that a reduction by $\geq 50 \%$ of myoclonic seizures may be achieved in $58.3 \%$ of patients. ${ }^{70}$ One Class III study reported the use of LEV among patients with rolandic epilepsy or variants: a $>50 \%$ reduction in seizure frequency was achieved by $62.5 \%$ of patients. ${ }^{71}$ There is no new recommended level of evidence for LEV under this indication.

A review of the behavioural side-effects of LEV revealed possible variation among paediatric and adult subjects. Nervousness, aggression, and hostile behaviour have been reported as putative behavioural adverse events. In paediatric cohorts, the proportion of such adverse events was $20 \%$ to $30 \% .^{70-72,94}$ By comparison, the behavioural sideeffects in adults were less prominent. ${ }^{72-75,94}$

Statement 6: The level of evidence for LEV adjunctive therapy remains unchanged (Level A).

\section{Oxcarbazepine}

One Class I study and three Class III studies (with mixed indications) were identified (Table $1^{12-19}$ ). In the study by the PROSPER Investigators Study Group, adjunctive OXC reduced seizure magnitude by $38.2 \%$ to $42.9 \%$. Adverse event rates and safety profiles suggested improved tolerability. ${ }^{95}$ Oxcarbazepine is currently licensed for adjunctive therapy in epilepsy and no change to the current recommended level of evidence was made.

Statement 7: The level of evidence for OXC adjunctive therapy remains unchanged (Level A).

\section{Lacosamide}

Three pivotal clinical studies outlined the clinical usefulness of LCS in patients with refractory epilepsy: one Phase II and two Phase III studies. ${ }^{76,96,97}$ These 12-week, randomised, double-blind, placebocontrolled, multicentre trials enrolled subjects with partial-onset seizures with or without secondary generalisation who were not adequately controlled with one to three concomitant AEDs. Study 1 compared doses of LCS 200, 400, and $600 \mathrm{mg} /$ day with placebo. ${ }^{96}$ Study 2 compared doses of LCS 400 and $600 \mathrm{mg} /$ day with placebo. ${ }^{76}$ Study 3 compared doses of LCS 200 and $400 \mathrm{mg} /$ day with placebo. ${ }^{97}$ Following an 8-week phase to establish baseline seizure frequency, subjects were titrated to the randomised dose. During the titration phase in all three trials, treatment was initiated at $100 \mathrm{mg} / \mathrm{day}$ (50 mg given twice daily) and increased by weekly increments of $100 \mathrm{mg} /$ day to the target dose. The titration phase lasted 6 weeks in Study 1 and Study 2 and 4 weeks in Study 3. In all three trials, the titration phase was followed by a maintenance phase for 12 weeks. The primary endpoint was reduction in 28-day seizure frequency (baseline to maintenance phase) compared with the placebo group. A statistically significant effect was observed with LCS treatment at doses of $200 \mathrm{mg} /$ day (Study 3), $400 \mathrm{mg} /$ day (Study 1, 2, and 3), and $600 \mathrm{mg} / \mathrm{day}$ (Study 1 and 2).

An observational phase IV open-label study to assess the efficacy, safety, tolerability, and additional outcomes of LCS in Hong Kong patients aged $\geq 18$ years showed that LCS had efficacy and adverse effects similar to those described in the literature from other parts of the world. In a cohort of 105 patients, the proportion who achieved a $50 \%$ reduction in seizure frequency was 54.5 with a mean titration time of 6.75 weeks and a mean maintenance dose of $158.6 \mathrm{mg} /$ day. The efficacy profile was satisfactory whether or not LCS was combined with concomitant sodium channel blockers $(45.8 \%$ vs 46.5\%). The side-effect profile included apprehension and aggression, drowsiness and tiredness, headache, memory problems, dizziness, numbness, and gait disturbance (local data).

Statement 8: The level of evidence for LCS as adjunctive therapy reaches Level A.

\section{Pregabalin}

Three Class I studies, four Class III studies, and four meta-analyses were found pertaining to PGB under this indication (Table $3^{14,46-57}$ ). One study evaluated the efficacy and tolerability of adjunctive PGB as a controlled-release formulation. The $50 \%$ responder rate (ie percentage of patients achieving 50\% reduction in seizure frequency) was $45.9 \%$ for a daily dose of $330 \mathrm{mg} .{ }^{98}$ Another randomised study tested PGB versus LEV in a head-to-head comparison in 409 patients. The drug PGB was non-inferior to LEV with a similar tolerability to LEV as adjunctive therapy. ${ }^{47}$ In a multicentre, randomised study of PGB versus placebo, PGB was effective and tolerable as adjunctive therapy in the Asian population. ${ }^{48}$ This drug is currently licensed for adjunctive therapy in epilepsy and there is no change to the level of evidence regarding its recommended use.

Statement 9: The level of evidence for PGB as adjunctive therapy remains unchanged (Level A).

\section{Perampanel}

A total of four Class I clinical studies demonstrated the efficacy of PER among patients with refractory epilepsy. ${ }^{58-61}$ These were all double-blind studies and all evaluated the $50 \%$ responder rate as a seizure 
TABLE 5. A review of the use of levetiracetam as an antiepileptic drug ${ }^{2-10,13,70-94}$

\begin{tabular}{|c|c|c|c|}
\hline Study & Class & Study population & Outcome \\
\hline \multicolumn{4}{|c|}{ Monotherapy. Level of evidence reached: A. Recommendation: changed from The Hong Kong Epilepsy Guideline 2009} \\
\hline Brodie et al, ${ }^{2} 2007$ & Class I & Adult & $\begin{array}{l}58.5 \% \text { Achieved seizure freedom with LEV. Withdrawal } \\
\text { rate of } 19.2 \% \text { with LEV }\end{array}$ \\
\hline Fattore et al, ${ }^{3} 2011$ & Class I & Paediatric & $23.7 \%$ Responders in LEV vs $4.8 \%$ of placebo \\
\hline Coppola et al, ${ }^{6} 2007$ & Class II & Paediatric, BECTS & LEV vs OXC \\
\hline Rosenow et al, ${ }^{4} 2012$ & Class II & Adult/paediatric & LEV = LTG \\
\hline Trinka et al, ${ }^{5} 2013$ & Class II & Adult & - \\
\hline Werhahn et al, ${ }^{8} 2015$ & Class II & Elderly & - \\
\hline Borggraefe et al, ${ }^{7} 2013$ & Class II & Paediatric & $\begin{array}{l}\text { LEV vs sulthiamine. Sample size not reached due to } \\
\text { limited recruitment }\end{array}$ \\
\hline Suresh et al, ${ }^{77} 2015$ & Class II & Adult & - \\
\hline Jung et al, ${ }^{78} 2015$ & Class II & Adult & - \\
\hline Chung et al, ${ }^{9} 2012$ & Class II & Adult & - \\
\hline Consoli et al, ${ }^{79} 2012$ & Class II & Post-stroke patients & - \\
\hline Hakami et al, ${ }^{80} 2012$ & Class II & Patients with substitution monotherapy & - \\
\hline Chung et al, ${ }^{76} 2016$ & Class III & Adult & - \\
\hline Zhu et al, ${ }^{10} 2015$ & Class III & Adult & - \\
\hline Xiao et al,,$^{81} 2014$ & Class III & Paediatric & - \\
\hline Kang et al, ${ }^{13} 2012$ & Class III & Paediatric & - \\
\hline Bertsche et al, ${ }^{82} 2014$ & Class III & Paediatric & - \\
\hline Stephen et al, ${ }^{83} 2011$ & Class III & Adult & - \\
\hline Verrotti et al, ${ }^{84} 2009$ & Class III & Paediatric & Effective for childhood occipital Gastaut type \\
\hline Belcastro et al, ${ }^{85} 2008$ & Class III & $\begin{array}{l}\text { Patients with late-onset post-stroke } \\
\text { seizures }\end{array}$ & $77.1 \%$ Achieved seizure freedom \\
\hline Verrotti et al, ${ }^{86} 2008$ & Class III & Paediatric (absence) & $\sim 50 \%$ Achieved seizure freedom \\
\hline Kutlu et al, ${ }^{87} 2008$ & Class III & Patients with late post-stroke seizures & 82.4\% Seizure-free \\
\hline Perry et al, ${ }^{88} 2008$ & Class III & Paediatric & LEV and CBZ had similar efficacy and well tolerated \\
\hline Verrotti et al, ${ }^{89} 2008$ & Class III & Paediatric/JME & $\sim 50 \%$ Achieved seizure freedom \\
\hline Belcastro et al, ${ }^{90} 2007$ & Class III & $\begin{array}{l}\text { Patients having Alzheimer's with late- } \\
\text { onset seizures }\end{array}$ & $16 \%$ Discontinuation rate \\
\hline Sharpe et al, ${ }^{91} 2008$ & Class III & JME & $8 \%$ Seizure-free \\
\hline Khurana et al, ${ }^{92} 2007$ & Class III & Paediatric & $61 \%$ Achieved seizure freedom \\
\hline Verrotti et al, ${ }^{93} 2007$ & Class III & BECTS & All patients were seizure-free or with reduction of $>50 \%$ \\
\hline \multicolumn{4}{|c|}{ Adjunctive therapy. Level of evidence reached: A. Recommendation: unchanged from The Hong Kong Epilepsy Guideline 2009} \\
\hline Noachtar et al, ${ }^{70} 2008$ & Class I & $\begin{array}{l}\text { Patients with idiopathic generalised } \\
\text { epilepsy }\end{array}$ & $50 \%$ Responder rate recorded in $58.3 \%$ \\
\hline Werhahn et al, ${ }^{73} 2011$ & Class III & Elderly & - \\
\hline Droz-Perroteau et al, ${ }^{74} 2011$ & Class III & Adult & - \\
\hline \multicolumn{4}{|l|}{ Mixed } \\
\hline von Stulpnagel et al, ${ }^{71} 2010$ & Class III & $\begin{array}{l}\text { Patients with rolandic epilepsy and } \\
\text { variants }\end{array}$ & 62.5\% Responded well \\
\hline Kuba et al, ${ }^{75} 2010$ & Class III & Adult & $11 \%$ Seizure-free and retention rate was $69.3 \%$ \\
\hline Lo et al, ${ }^{94} 2011$ & Meta-analysis & - & - \\
\hline Mbizvo et al, ${ }^{72} 2012$ & Meta-analysis & - & - \\
\hline
\end{tabular}

Abbreviations: BECTS = benign epilepsy of childhood with centrotemporal spikes; CBZ = carbamazepine; JME = juvenile myoclonic epilepsy; LEV = levetiracetam; $\mathrm{LTG}=$ lamotrigine; $\mathrm{OXC}=$ oxcarbazepine 
outcome. The corresponding risk ratio for $50 \%$ responder rate for $4 \mathrm{mg}, 8 \mathrm{mg}$, and $12 \mathrm{mg}$ were $1.54,1.8$, and 1.72 . The most common treatmentemergent adverse effects were dizziness, drowsiness, headache, fatigue, and nasopharyngitis. The pooled results suggested that a higher dose was more efficacious if the side-effects could be tolerated. ${ }^{62}$ There was one ongoing study on the use of PER among patients with secondary generalised seizures.

Statement 10: The level of evidence for PER as adjunctive therapy reaches Level A.

\section{Part B: Generic drugs}

The last version of the The Hong Kong Epilepsy Guideline gave advice on the use of generic drugs, details of which can be revisited in the original guideline of 2009. ${ }^{1}$ There might be a perceived difference between pharmaceutical equivalence, which is the requirement of the exact product, and bioequivalence, which is the concept of assigning no difference among products in terms of drug absorption. There have been positional statements that outline the possible risks involved when switching antiepileptic agents from a brand to a generic preparation. ${ }^{99}$ Clinicians are understandably perturbed by the prospect of inadvertent seizures and loss of quality of life for their patients. The criteria applied by authorities to license generic products give rise to various issues. For instance, the concept of bioequivalence does not require the generic product to demonstrate clinical efficacy among patients. Most bioequivalence studies are performed among healthy subjects rather than individual patients. Antiepileptic drugs are placed in the same category as immunosuppressants and psychotropic drugs, in which generic substitution is necessarily given consideration before implementation. The benefit of generic AEDs is clear in countries where health care financing is either state-run or public-funded, but may still be important in terms of patient choice in countries where private health care or an insurancebased system is practised because patients may want to lower their premium by using generic products. It may be argued that the use of generic products will increase the potential availability of drugs to a broader population of patients including those who are underprivileged or resident in communities where the drug budget is restricted.

There is a growing need for review and update of recommended guidelines on issues related to generic products as the evidence for newer drugs has become more eminent. The prescription of and expenditure on newer agents has risen sharply over the last 5 to 10 years. Clinicians now have a far greater number of AEDs at their disposal compared with a decade ago. There is divided opinion in the professional community about the use of generic products and when it will be considered optimal and safe for epilepsy patients. In general, communities that rely on a state-financed or government-funded health care system are under greater pressure to consider generic product prescription, compared with private-funded or out-of-pocket payment health care financing systems.

Our literature search identified 13 studies published in or after 2007 that fulfilled the initial inclusion criteria. Four studies were of the Class I category, one of the Class II category, and eight of the Class III category (Table $6^{100-116}$ ). Six studies had LTG as the study AED. ${ }^{100-105}$ Two studies had topiramate as the study focus ${ }^{106,115}$ and the remaining studies adopted multiple drug regimens. ${ }^{107-111} \mathrm{~A}$ good level of evidence came from a randomised controlled trial of 'generic-brittle' patients in a double-blind, multiple-dose, steady-state, fully replicated crossover bioequivalence study of LTG. The study demonstrated that the generic product was bioequivalent to the brand medication. Such observations were supported by the secondary outcomes of seizure control and tolerability-32 of 35 patients reported no deterioration of seizures, and dose-related adverse events were experienced by 14 patients while on the generic product and 15 patients while on the brand product. The study highlighted the use of the therapeutic level as a guide over a period of time while the patient is switched from brand to generic or vice versa. ${ }^{100}$ Two Class I studies with preliminary results disseminated during the annual meeting of the American Epilepsy Society in 2015 showed no deviation from FDA's bioequivalence standards in $\mathrm{C}_{\max }$ and area under the curve when comparing two most disparate generic products in a single dose and chronic disease model respectively (methodology given in Diaz et al in $2013^{101}$ ). One well-designed study of 35 patients randomised patients from six epilepsy centres to receive LTG as one of two treatment sequences that comprised four study periods of 14 days each, during which time balanced doses of an oral generic LTG product were given every 12 hours. Disparate generic LTG in patients with epilepsy demonstrated bioequivalence with no detectable difference in clinical effects. ${ }^{102}$ A similar result was found from the only Class II study from our literature search. ${ }^{103}$ The best level of evidence in epilepsy patients supported the switch of LTG (sodium channel blocker) from brand to generic preparation. It remains controversial whether these findings can be extrapolated to other AEDs because LTG is by far one of the most widely used first-line AEDs.

Most Class III studies indicated an opposite result compared with the Class I and II studies. These studies showed that generic substitution may result in increased acute seizure-related events and higher use of medical services. The switch-back rates for AEDs from generic to brand were higher in these 
TABLE 6. Compilation of studies published in 2007 or after related to human studies of generic preparations of antiepileptic drugs ${ }^{100-1 / 6}$

\begin{tabular}{|c|c|c|}
\hline Class & Type and No. of subjects & Results \\
\hline \multicolumn{3}{|l|}{ Class I studies } \\
\hline Piñeyro-López et al, ${ }^{115} 2009$ & Class I, 28 subjects (TPM) & $\begin{array}{l}\text { Pharmacokinetic sampling up to } 6 \text { days per formula } \\
\text { Pharmacokinetic and clinical outcomes not significantly different }\end{array}$ \\
\hline Privitera et al, ${ }^{102} 2016$ & $\begin{array}{l}\text { Class I, } 35 \text { patients (EQUIGEN chronic- } \\
\text { dose study) [multiple regimens of LTG] }\end{array}$ & $\begin{array}{l}\text { No loss of seizure control, no unexpected adverse effects, and } \\
\text { standardised side-effect measure scores were not different } \\
\text { between generics }\end{array}$ \\
\hline Diaz et al, ${ }^{101} 2013$ & $\begin{array}{l}\text { Class I, } 50 \text { subjects (EQUIGEN single- } \\
\text { dose study) [LTG] }\end{array}$ & $\begin{array}{l}\text { Bioequivalence among brand to high generic, brand to low generic, } \\
\text { and high to low generic shown. No outliers and no serious adverse } \\
\text { effects }\end{array}$ \\
\hline Ting et al, ${ }^{100} 2015$ & Class I, 35 patients (LTG) & $\begin{array}{l}\text { Selection of 'generic-brittle' patients. Pharmacokinetic profiles for } \\
\text { brand and generic at the end of } 2 \text {-week treatment period. Generic } \\
\text { was bioequivalent to the brand. } 32 / 35 \text { in the ITT group reported no } \\
\text { worsening of seizures. Dose-related adverse effects were similar } \\
\text { between generic and brand }\end{array}$ \\
\hline
\end{tabular}

\section{Class II studies}

Srichaiya et al, ${ }^{103} 2008 \quad$ Class II, 28 subjects (LTG)

Lamotrigine used. No significant change in pharmacokinetic and clinical parameters

Class III studies

Andermann et al, ${ }^{104} 2007$

LeLorier et al, ${ }^{105} 2008$

Zachry et al, ${ }^{107} 2009$

Duh et al, ${ }^{106} 2009$

Rascati et al, ${ }^{108} 2009$

Labiner et al, ${ }^{109} 2010$

Gagne et al, ${ }^{110} 2010$

Chaluvadi et al, ${ }^{111} 2011$
Class III, 1142 subjects (LTG)

Class III, 671 subjects (LTG)

Class III, 416 subjects (multiple drugs)

Class III, 948 subjects (TPM)

Class III, 991 subjects (multiple drugs)

Class III, 33625 subjects (multiple drugs)

Class III, 1762 subjects (multiple drugs)

Class III, 260 subjects
More adverse effects with generic drug

Higher use of medical services and longer hospital stay with generic drugs

More epilepsy-related acute care required for generic drugs

Additional AEDs required if generic drug was prescribed; length of hospital stay was longer

Similar results to Zachry et al in $2009^{107}$

High risk of using medical resources if generic preparation was used, longer hospital stay, and more out-patient visits

Higher risk of epilepsy-related outcomes

A higher proportion of patients had to switch back to brand preparations due to adverse effects

Other consensus statements

Cañadillas-Hidalgo et al, ${ }^{116} 2009$

Not replacing innovative AED by its generic

Position statement from American Acknowledged the bioequivalence of brand and FDA-approved generic products. Substitution might reduce Epilepsy Society ${ }^{114}$ cost without affecting efficacy

Position statement from Italian Automatic switching of brand to generic AED not recommended

League Against Epilepsy ${ }^{112}$

Position statement from French

Chapter of International League

Against Epilepsy ${ }^{113}$

Uniqueness of epilepsy as a class of disease in which generic substitution is problematic

Abbreviations: AED = antiepileptic drug; FDA = Food and Drug Administration; ITT = intention-to-treat; LTG = lamotrigine;TPM = topiramate

studies. Of note, these studies had larger sample the Medicine and Healthcare products Regulatory sizes but all the studies were retrospective in nature. Agency, issued guidelines regarding the use of These studies might also have involved a wide range generic products in 2013 and specifically divided of prescribing practices and some patient factors AEDs into three categories, each of which had might not have been taken into account.

Overall, most studies suggested bioequivalence of brand and generic AEDs. This result was also in keeping with a meta-analysis which concluded that if only the highest level of evidence is considered, there is no significant difference in terms of seizure control, whether or not the patient is taking brand or generic products. ${ }^{117}$ A UK pharmacovigilance body, specific recommendations regarding the switching of brand to generic products (Appendix). ${ }^{118}$ Category 1 relates to products among which a specific manufacturer's product should be ensured (eg phenytoin, carbamazepine, phenobarbital, and primidone). Category 2 relates to products for which generic switching is considered neutral, but clinical judgement should be exercised in so doing 
(eg sodium valproate, LTG, OXC, topiramate). Category 3 relates to products for which generic substitution is considered safe (eg LEV, gabapentin) [Table $6^{100-116}$. The UK National Institute for Health and Care Excellence guideline ${ }^{119}$ recommended that a consistent supply should be made available to the epilepsy patient unless the prescriber, in consultation with the patient, considers that this is not a concern.

We acknowledge the controversy about switching from a brand to a generic product. There appears to be a divide in the positional statements and guidelines between countries with public-funded health care and those with private health care. Many associations, including the Italian League Against Epilepsy, ${ }^{112}$ American Academy of Neurology, ${ }^{114}$ and the French Chapter of ILAE ${ }^{113}$ have expressed concerns about generic substitution of AEDs, emphasising the uniqueness of epilepsy as a class of disease in which generic substitution is problematic when carried out for this indication. The latest position statement from the American Epilepsy Society acknowledges the bioequivalence of brand and FDA-approved generic products and the fact that substitution may reduce cost without compromising efficacy. The Society advises the importance of using either immediate-release or extended-release preparations uniformly throughout the switching process. They acknowledge that tablet or capsule colour or shape may impact drug compliance. They also state that the counselling of switching should include an indication of bioequivalence and not inferiority when the information is conveyed to the patient(s) and their family members. ${ }^{114}$

A pilot study pioneered by the Hospital Authority Head Office on the switching of phenytoin from a generic back to a brand product due to supplier issues suggested that proper counselling and followup logistics in conjunction with a pre- and post-drug level at 2 weeks may be adequate for the exercise. In 40 patients recruited from the Prince of Wales Hospital and Queen Mary Hospital, no patients developed a toxic level of plasma phenytoin during the switching process (four patients had a toxiclevel pre-switching that remained post-switching). Plasma phenytoin concentration increased in 23 patients and decreased in 17 . The conclusion was that there was no consistent trend in the change of plasma drug level (personal communication). Apart from isolated cases of reported dizziness, no serious adverse event occurred. The rate of hospitalisation as a result of the switch in that study was not available to us at the time of writing this review.

Statement 11: There is Level A evidence for generic substitution of LTG (a sodium channel blocker), taking into account the drug's pharmacodynamics and pharmacokinetics.

The HKES upholds the safety of patients above all else. Following a review of the current evidence, the HKES has made the following revisions for the reference of physicians. Doctors can initiate treatment in patients with epilepsy with either a brand or generic product. Switching from a brand to a generic product or between generic products requires great care by clinicians and health care administrators. Automatic substitution at a pharmacy level is not recommended. If switching takes place as a result of cost considerations, prescriber and patient approval must be sought, in liaison with the pharmacist. Prescriber approval is not equivalent to a medical decision. The course of treatment, including choice of drug and dosage, is determined by the doctor and forms part of a medical decision. When the use of generic drugs is based on cost-effective analyses, prescriber approval is a logistic and economic decision. Depending on the type of health care setting, a request for generic substitution may begin with the patient or the health administrator, in liaison with the attending doctor/ pharmacist. Patient approval may not be equivalent to medical consent. This can be a requirement of the health care system to which the patient belongs or a self-initiated step from the patient who has subscribed to insurance plans with affordable premiums. The physician should discuss any switch with the patient from both a medical and layman's perspective. Good communication is considered fundamental to the provision of care. ${ }^{120}$ Therefore, in a private health care system, the choice for generic drugs may begin with a patient's request, followed by prescriber approval. In a public health care system, the choice for generic drugs may begin with prescriber's request, followed by patient approval. Follow-up and monitoring logistics should be mutually agreed to ensure patient safety. A change in the physical appearance of medications may hinder compliance. This facet of the switch must be taken into account by all parties. In the special situation where switching from a brand to a generic product takes place among patients who have achieved remission while on antiepileptic therapy, clinicians must take into account the drug's pharmacokinetics and the support of medical services. Assistance from nursing staff, enlisting therapeutic blood monitoring, and the option to use the AED as a self-financed item (both public and private setting) should be made available.

Statement 12: Controversy exists over the use of generic products among patients who are currently taking brand medications. Prescriber and patient approval is pivotal. There should be good communication between doctors and patients; enlisting assistance from doctors, nurses, and pharmacists; therapeutic blood monitoring if available; and the option of brand AED as a selffinanced item. The physical appearance of generic drugs may hamper drug compliance. Support from 
medical services is recommended. In the longer term, the benefit of flexibility and the option to have balanced use of generic and brand drugs may need to be addressed by institutions and regulatory bodies.

\section{Conclusions}

New evidence on AEDs has arisen since the publication of the Hong Kong Epilepsy Guideline in 2009. There is Level A evidence for LEV monotherapy and Level B evidence for LCS monotherapy. There is Level A evidence for LCS and PER adjunctive therapy. No change to the level of evidence is evident for LEV, $\mathrm{OXC}$, and PGB. The use of generic preparations of AEDs should be considered following prescriber and patient approval, with support from medical services (doctors, nurses, pharmacists). It is important to emphasise that a generic preparation is not inferior, that shape and colour of tablets may be different, there may be therapeutic blood monitoring (if available), and patients may have the option of selffinancing items.

\section{Appendix}

Additional material related to this article can be found on the HKMJ website. Please go to <http:// www.hkmj.org>, and search for the article.

\section{Acknowledgement}

This project was supported in part by an unrestricted grant from the Hong Kong Epilepsy Society.

\section{Disclaimer}

This consensus statement is designed to assist clinicians by providing an analytical framework for the drug treatment of epilepsy. It is not intended to establish a community standard of care, replace a clinician's medical judgement, or establish a protocol for all patients.

\section{References}

1. Guideline Development Group, Hong Kong Epilepsy Society. The Hong Kong Epilepsy Guideline 2009. Hong Kong Med J 2009;15 Suppl 5:6S-28S.

2. Brodie MJ, Perucca E, Ryvlin P, et al. Comparison of levetiracetam and controlled-release carbamazepine in newly diagnosed epilepsy. Neurology 2007;68:402-8.

3. Fattore C, Boniver C, Capovilla G, et al. A multicenter, randomized, placebo-controlled trial of levetiracetam in children and adolescents with newly diagnosed absence epilepsy. Epilepsia 2011;52:802-9.

4. Rosenow F, Schade-Brittinger C, Burchardi N, et al. The LaLiMo Trial: lamotrigine compared with levetiracetam in the initial 26 weeks of monotherapy for focal and generalised epilepsy-an open label, prospective, randomised controlled multicenter study. J Neurol Neurosurg Psychiatry 2012;83:1093-8.

5. Trinka E, Marson AG, Van Paesschen W, et al. KOMET: an unblinded, randomised, two parallel-group, stratified trial comparing the effectiveness of levetiracetam with controlled-release carbamazepine and extended-release sodium valproate as monotherapy in patients with newly diagnosed epilepsy. J Neurol Neurosurg Psychiatry 2013;84:1138-47.

6. Coppola G, Franzoni E, Verrotti A, et al. Levetiracetam or oxcarbazepine as monotherapy in newly diagnosed benign epilepsy of childhood with centrotemporal spikes (BECTS): An open-label, parallel group trial. Brain Dev 2007;29:281-4.

7. Borggraefe I, Bonfert M, Bast T, et al. Levetiracetam vs. sulthiame in benign epilepsy with centrotemporal spikes in childhood: A double-blinded, randomized, controlled trial (German HEAD study). Eur J Paediatr Neurol 2013;17:507-14.

8. Werhahn KJ, Trinka E, Dobesberger J, et al. A randomized, double-blind comparison of antiepileptic drug treatment in the elderly with new-onset focal epilepsy. Epilepsia 2015;56:450-9.

9. Chung S, Ceja H, Gawlowicz J, et al. Levetiracetam extended release conversion to monotherapy for the treatment of patients with partial-onset seizures: A double-blind, randomised, multicentre, historical control study. Epilepsy Res 2012;101:92-102.

10. Zhu F, Lang SY, Wang XQ, et al. Long-term effectiveness of antiepileptic drug monotherapy in partial epileptic patients: A 7-year study in an epilepsy center in China. Chin Med J (Engl) 2015;128:3015-22.

11. Glauser T, Ben-Menachem E, Bourgeois B, et al. Updated ILAE evidence review of antiepileptic drug efficacy and effectiveness as initial monotherapy for epileptic seizures and syndromes. Epilepsia 2013;54:551-63.

12. Franzoni E, Gentile V, Pellicciari A, et al. Prospective study on long-term treatment with oxcarbazepine in pediatric epilepsy. J Neurol 2009;256:1527-32.

13. Kang HC, Hu Q, Liu XY, et al. A follow-up study on newer anti-epileptic drugs as add-on and monotherapy for partial epilepsy in China. Chin Med J (Engl) 2012;125:64651.

14. French J, Kwan P, Fakhoury T, et al. Pregabalin monotherapy in patients with partial-onset seizures: a historical-controlled trial. Neurology 2014;82:590-7.

15. Koch MW, Polman SK. Oxcarbazepine versus carbamazepine monotherapy for partial onset seizures. Cochrane Database Syst Rev 2009;(4):CD006453.

16. Eun SH, Kim HD, Chung HJ, et al. A multicenter trial of oxcarbazepine oral suspension monotherapy in children newly diagnosed with partial seizures: A clinical and cognitive evaluation. Seizure. 2012;21:679-84.

17. Dogan EA, Usta BE, Bilgen R, Senol Y, Aktekin B. Efficacy, tolerability, and side effects of oxcarbazepine monotherapy: A prospective study in adult and elderly patients with newly diagnosed partial epilepsy. Epilepsy Behav 2008;13:156-61.

18. Lee SA, Heo K, Kim WJ, et al. Clinical feasibility of immediate overnight switching from slow-release carbamazepine to oxcarbazepine in Korean patients with refractory partial epilepsy. Seizure 2010;19:356-8.

19. Seneviratne U, D'Souza W, Cook M. Long-term assessment of oxcarbazepine in a naturalistic setting: a retrospective study. Acta Neurol Scand 2008;117:3679. 
20. Wechsler RT, Li G, French J, et al. Conversion to lacosamide monotherapy in the treatment of focal epilepsy: Results from a historical-controlled, multicenter, double-blind study. Epilepsia 2014;55:1088-98.

21. Giráldez BG, Toledano R, García-Morales I, et al. Longterm efficacy and safety of lacosamide monotherapy in the treatment of partial-onset seizures: a multicenter evaluation. Seizure 2015;29:119-22.

22. Lattanzi S, Cagnetti C, Foschi N, Provinciali L, Silvestrini M. Lacosamide monotherapy for partial onset seizures. Seizure 2015;27:71-4.

23. Husain A, Chung S, Faught E, Isojarvi J, McShea C, Doty P. Long-term safety and efficacy in patients with uncontrolled partial-onset seizures treated with adjunctive lacosamide: results from a Phase III open-label extension trial. Epilepsia 2012;53:521-8.

24. Runge U, Arnold S, Brandt C, et al. A noninterventional study evaluating the effectiveness and safety of lacosamide added to monotherapy in patients with epilepsy with partial-onset seizures in daily clinical practice: The VITOBA study. Epilepsia 2015;56:1921-30.

25. Stephen LJ, Kelly K, Parker P, Brodie MJ. Adjunctive lacosamide -5 years' clinical experience. Epilepsy Res 2014;108:1385-91.

26. Pasha I, Kamate M, Didagi SK. Efficacy and tolerability of lacosamide as an adjunctive therapy in children with refractory partial epilepsy. Pediatr Neurol 2014;51:509. 14.

27. Rosenfeld W, Fountain NB, Kaubrys G, et al. Safety and efficacy of adjunctive lacosamide among patients with partial-onset seizures in a long-term open-label extension trial of up to 8 years. Epilepsy Behav 2014;41:164-70.

28. Gulati P, Cannell P, Ghia T, et al. Lacosamide as adjunctive therapy in treatment-resistant epilepsy in childhood. J Paediatr Child Health 2015;51:794-7.

29. Rosenow F, Kelemen A, Ben-Menachem E, et al. Longterm adjunctive lacosamide treatment in patients with partial-onset seizures. Acta Neurol Scand 2015 Jul 2. Epub ahead of print.

30. Geffrey AL, Belt OD, Paolini JL, Thiele EA. Lacosamide use in the treatment of refractory epilepsy in tuberous sclerosis complex. Epilepsy Res 2015;112:72-5.

31. Flores L, Kemp S, Colbeck K, et al. Clinical experience with oral lacosamide as adjunctive therapy in adult patients with uncontrolled epilepsy: a multicentre study in epilepsy clinics in the United Kingdom (UK). Seizure 2012;21:512-7.

32. Kamel JT, DeGruyter MA, D’Souza WJ, Cook MJ. Clinical experience with using lacosamide for the treatment of epilepsy in a tertiary centre. Acta Neurol Scand 2013;127:149-53.

33. Verrotti A, Loiacono G, Pizzolorusso A, et al. Lacosamide in pediatric and adult patients: comparison of efficacy and safety. Seizure 2013;22:210-6.

34. Toupin JF, Lortie A, Major P, et al. Efficacy and safety of lacosamide as an adjunctive therapy for refractory focal epilepsy in paediatric patients: a retrospective singlecentre study. Epileptic Disord 2015;17:436-43.

35. Zadeh WW, Escartin A, Byrnes W, et al. Efficacy and safety of lacosamide as first add-on or later adjunctive treatment for uncontrolled partial-onset seizures: A multicentre open-label trial. Seizure 2015;31:72-9.

36. Rastogi RG, Ng YT. Lacosamide in refractory mixed pediatric epilepsy: a prospective add-on study. J Child Neurol 2012;27:492-5.

37. Grosso S, Parisi P, Spalice A, Verrotti A, Balestri P. Efficacy and safety of lacosamide in infants and young children with refractory focal epilepsy. Eur J Paediatr Neurol 2014;18:55-9.

38. Grosso S, Coppola G, Cusmai R, et al. Efficacy and tolerability of add-on lacosamide in children with LennoxGastaut syndrome. Acta Neurol Scand 2014;129:420-4.

39. Lee JW, Alam J, Llewellyn $\mathrm{N}$, et al. Open label trial of add on lacosamide versus high dose levetiracetam monotherapy in patients with breakthrough seizures. Clin Neuropharmacol 2016;39:128-31.

40. Buck ML, Goodkin HP. Use of lacosamide in children with refractory epilepsy. J Pediatr Pharmacol Ther 2012;17:211-9.

41. Paquette V, Culley C, Greanya ED, Ensom MH. Lacosamide as adjunctive therapy in refractory epilepsy in adults: a systematic review. Seizure 2015;25:1-17.

42. Biton V, Gil-Nagel A, Isojarvi J, et al. Safety and tolerability of lacosamide as adjunctive therapy for adults with partial-onset seizures: Analysis of data pooled from three randomized, double-blind, placebo-controlled clinical trials. Epilepsy Behav 2015;52:119-27.

43. Sawh SC, Newman JJ, Deshpande S, Jones PM. Lacosamide adjunctive therapy for partial-onset seizures: a meta-analysis. PeerJ 2013;1:e114.

44. Yorns WR Jr, Khurana DS, Carvalho KS, Hardison HH, Legido A, Valencia I. Efficacy of lacosamide as adjunctive therapy in children with refractory epilepsy. J Child Neurol 2014;29:23-7.

45. Novy J, Bartolini E, Bell GS, Duncan JS, Sander JW. Long-term retention of lacosamide in a large cohort of people with medically refractory epilepsy: a single centre evaluation. Epilepsy Res 2013;106:250-6.

46. Kwan P, Brodie MJ, Kälviäinen R, Yurkewicz L, Weaver J, Knapp LE. Efficacy and safety of pregabalin versus lamotrigine in patients with newly diagnosed partial seizures: a phase 3 , double-blind, randomised, parallelgroup trial. Lancet Neurol 2011;10:881-90.

47. Zaccara G, Almas M, Pitman V, Knapp L, Posner H. Efficacy and safety of pregabalin versus levetiracetam as adjunctive therapy in patients with partial seizures: a randomized, double-blind, noninferiority trial. Epilepsia 2014;55:1048-57.

48. Lee BI, Yi S, Hong SB, et al. Pregabalin add-on therapy using a flexible, optimized dose schedule in refractory partial epilepsies: a double-blind, randomized, placebocontrolled, multicenter trial. Epilepsia 2009;50:464-74.

49. Zhou Q, Zheng J, Yu L, Jia X. Pregabalin monotherapy for epilepsy. Cochrane Database Syst Rev 2012;(10):CD009429.

50. Valentin A, Moran N, Hadden R, et al. Pregabalin as adjunctive therapy for partial epilepsy: an audit study in 96 patients from the South East of England. Seizure 2009;18:450-2.

51. Tsounis S, Kimiskidis VK, Kazis D, et al. An open-label, add-on study of pregabalin in patients with partial seizures: a multicenter trial in Greece. Seizure 2011;20:701-5.

52. Stephen LJ, Parker P, Kelly K, Wilson EA, Leach V, Brodie MJ. Adjunctive pregabalin for uncontrolled partial-onset seizures: findings from a prospective audit. Acta Neurol Scand 2011;124:142-5. 
53. Ryvlin P, Kälviäinen R, Von Raison F, Giordano S, Emir B, Chatamra K. Pregabalin in partial seizures: a pragmatic 21-week, open-label study (PREPS). Eur J Neurol 2010;17:726-32.

54. Pulman J, Hemming K, Marson AG. Pregabalin add-on for drug-resistant partial epilepsy. Cochrane Database Syst Rev 2014;(3):CD005612.

55. Lozsadi D, Hemming K, Marson AG. Pregabalin add-on for drug-resistant partial epilepsy. Cochrane Database Syst Rev 2008;(1):CD005612.

56. Gil-Nagel A, Zaccara G, Baldinetti F, Leon T. Add-on treatment with pregabalin for partial seizures with or without generalisation: pooled data analysis of four randomised placebo-controlled trials. Seizure 2009;18:184-92.

57. Uthman BM, Bazil CW, Beydoun A, et al. Long-term add-on pregabalin treatment in patients with partialonset epilepsy: pooled analysis of open-label clinical trials. Epilepsia 2010;51:968-78.

58. French JA, Krauss GL, Wechsler RT, et al. Perampanel for tonic-clonic seizures in idiopathic generalized epilepsy. A randomized trial. Neurology 2015;85:950-7.

59. French JA, Krauss GL, Steinhoff BJ, et al. Evaluation of adjunctive perampanel in patients with refractory partialonset seizures: results of randomized global phase III study 305. Epilepsia 2013;54:117-25.

60. French JA, Krauss GL, Biton V, et al. Adjunctive perampanel for refractory partial-onset seizures. Randomized phase III study 304. Neurology 2012;79:58996.

61. Krauss GL, Serratosa JM, Villanueva V, et al. Randomized phase III study 306. Adjunctive perampanel for refractory partial-onset seizures. Neurology 2012;78:1408-15.

62. Kwan P, Brodie MJ, Laurenza A, FitzGibbon H, Gidal BE. Analysis of pooled phase III trials of adjunctive perampanel for epilepsy: Impact of mechanism of action and pharmacokinetics on clinical outcomes. Epilepsy Res 2015;117:117-24.

63. Juhl S, Rubboli G. Perampanel as add-on treatment in refractory focal epilepsy. The Dianalund experience. Acta Neurol Scand 2016;134:374-7.

64. Brodie MJ, Stephen LJ. Prospective audit with adjunctive perampanel: Preliminary observations in focal epilepsy. Epilepsy Behav 2016;54:100-3.

65. Shah E, Reuber M, Goulding P, Flynn C, Delanty N, Kemp S. Clinical experience with adjunctive perampanel in adult patients with uncontrolled epilepsy: A UK and Ireland multicentre study. Seizure 2016;34:1-5.

66. Steinhoff BJ, Hamer H, Trinka E, et al. A multicenter survey of clinical experiences with perampanel in real life in Germany and Austria. Epilepsy Res 2014;108:986-8.

67. Kramer LD, Satlin A, Krauss GL, et al. Perampanel for adjunctive treatment of partial-onset seizures: A pooled dose-response analysis of phase III studies. Epilepsia 2014;55:423-31.

68. Steinhoff BJ, Bacher M, Bast $\mathrm{T}$, et al. First clinical experiences with perampanel-The Kork experience in 74 patients. Epilepsia 2014;55 Suppl 1:16-8.

69. Hsu WW, Sing CW, He Y, Worsley AJ, Wong IC, Chan EW. Systematic review and meta-analysis of the efficacy and safety of perampanel in the treatment of partial-onset epilepsy. CNS Drugs 2013;27:817-27.

70. Noachtar S, Andermann E, Meyvisch P, et al. Levetiracetam for the treatment of idiopathic generalized epilepsy with myoclonic seizures. Neurology 2008;70:607-16.

71. von Stulpnagel C, Kluger G, Leiz S, Holthausen H. Levetiracetam as add-on therapy in different subgroups of "benign" idiopathic focal epilepsies in childhood. Epilepsy Behav 2010;17:193-8.

72. Mbizvo GK, Dixon P, Hutton JL, Marson AG. Levetiracetam add-on for drug-resistant focal epilepsy: an updated Cochrane Review. Cochrane Database Syst Rev 2012;(9):CD001901.

73. Werhahn KJ, Klimpe S, Balkaya S, Trinka E, Krämer G. The safety and efficacy of add-on levetiracetam in elderly patients with focal epilepsy: A one-year observational study. Seizure 2011;20:305-11.

74. Droz-Perroteau C, Dureau-Pournin C, Vespignani H, et al. The EULEV cohort study: rates of and factors associated with continuation of levetiracetam after 1 year. Br J Clin Pharmacol 2011;71:121-7.

75. Kuba R, Novotná I, Brázdil $M$, et al. Long-term levetiracetam treatment in patients with epilepsy: 3-year follow up. Acta Neurol Scand 2010;121:83-8.

76. Chung S, Ceja H, Gawłowicz J, McShea C, Schiemann J, $\mathrm{Lu}$ S. Levetiracetam extended release for the treatment of patients with partial-onset seizures: A long-term, openlabel follow-up study. Epilepsy Res 2016;120:7-12.

77. Suresh SH, Chakraborty A, Virupakshaiah A, Kumar N. Efficacy and safety of levetiracetam and carbamazepine as monotherapy in partial seizures. Epilepsy Res Treat 2015;2015:415082.

78. Jung DE, Yu R, Yoon JR, et al. Neuropsychological effects of levetiracetam and carbamazepine in children with focal epilepsy. Neurology 2015;84:2312-9.

79. Consoli D, Bosco D, Postorino P, et al. Levetiracetam versus carbamazepine in patients with late poststroke seizures: a multicenter prospective randomized openlabel study (EpIC Project). Cerebrovasc Dis 2012;34:2829.

80. Hakami T, Todaro M, Petrovski S, et al. Substitution monotherapy with levetiracetam vs older antiepileptic drugs: A randomized comparative trial. Arch Neurol 2012;69:1563-71.

81. Xiao F, An D, Deng H, Chen S, Ren J, Zhou D. Evaluation of levetiracetam and valproic acid as low-dose monotherapies for children with typical benign childhood epilepsy with centrotemporal spikes (BECTS). Seizure 2014;23:756-61.

82. Bertsche A, Neininger MP, Dahse AJ, et al. Initial anticonvulsant monotherapy in routine care of children and adolescents: levetiracetam fails more frequently than valproate and oxcarbazepine due to a lack of effectiveness. Eur J Pediatr 2014;173:87-92.

83. Stephen LJ, Kelly K, Parker P, Brodie MJ. Levetiracetam monotherapy-outcomes from an epilepsy clinic. Seizure 2011;20:554-7.

84. Verrotti A, Parisi P, Loiacono G, et al. Levetiracetam monotherapy for childhood occipital epilepsy of gastaut. Acta Neurol Scand 2009;120:342-6.

85. Belcastro V, Costa C, Galletti F, et al. Levetiracetam in newly diagnosed late-onset post-stroke seizures: A prospective observational study. Epilepsy Res 2008;82:223-6.

86. Verrotti A, Cerminara C, Domizio S, et al. Levetiracetam in absence epilepsy. Dev Med Child Neurol 2008;50:850- 
87. Kutlu G, Gomceli YB, Unal Y, Inan LE. Levetiracetam monotherapy for late poststroke seizures in the elderly. Epilepsy Behav 2008;13:542-4.

88. Perry S, Holt P, Benatar M. Levetiracetam versus carbamazepine monotherapy for partial epilepsy in children less than 16 years of age. J Child Neurol 2008;23:515-9.

89. Verrotti A, Cerminara C, Coppola G, et al. Levetiracetam in juvenile myoclonic epilepsy: long-term efficacy in newly diagnosed adolescents. Dev Med Child Neurol 2008;50:29-32.

90. Belcastro V, Costa C, Galletti F, et al. Levetiracetam monotherapy in Alzheimer patients with late-onset seizures: a prospective observational study. Eur J Neurol 2007;14:1176-8.

91. Sharpe DV, Patel AD, Abou-Khalil B, Fenichel GM. Levetiracetam monotherapy in juvenile myoclonic epilepsy. Seizure 2008;17:64-8.

92. Khurana DS, Kothare SV, Valencia I, Melvin JJ, Legido A. Levetiracetam monotherapy in children with epilepsy. Pediatr Neurol 2007;36:227-30.

93. Verrotti A, Coppola G, Manco R, et al. Levetiracetam monotherapy for children and adolescents with benign rolandic seizures. Seizure 2007;16:271-5.

94. Lo BW, Kyu HH, Jichici D, Upton AM, Akl EA, Meade MO. Meta-analysis of randomized trials on first line and adjunctive levetiracetam. Can J Neurol Sci 2011;38:47586.

95. French JA, Baroldi P, Brittain ST, Johnson JK; PROSPER Investigators Study Group. Efficacy and safety of extended-release oxcarbazepine (Oxtellar XR) as adjunctive therapy in patients with refractory partialonset seizures: a randomized controlled trial. Acta Neurol Scand 2014;129:143-53.

96. Ben-Menachem E, Biton V, Jatuzis D, Abou-Khalil B, Doty P, Rudd GD. Efficacy and safety of oral lacosamide as adjunctive therapy in adults with partial-onset seizures. Epilepsia 2007;48:1308-17.

97. Halász P, Kälviäinen R, Mazurkiewicz-Beldzińska M, et al. Adjunctive lacosamide for partial-onset seizures: efficacy and safety results from a randomized controlled trial. Epilepsia 2009;50:443-53.

98. French J, Brandt C, Friedman D, et al. Adjunctive use of controlled-release pregabalin in adults with treatmentresistant partial seizures: a double-blind, randomized, placebo-controlled trial. Epilepsia 2014;55:1220-8.

99. Liow K, Barkley GL, Pollard JR, Harden CL, Bazil CW; American Academy of Neurology. Position statement on the coverage of anticonvulsant drugs for the treatment of epilepsy. Neurology 2007;68:1249-50.

100. Ting TY, Jiang W, Lionberger R, et al. Generic lamotrigine versus brand-name Lamictal bioequivalence in patients with epilepsy: A field test of the FDA bioequivalence standard. Epilepsia 2015;56:1415-24.

101. Diaz FJ, Berg MJ, Krebill R, et al. Random-effects linear modeling and sample size tables for two special crossover designs of average bioequivalence studies: the four-period, two-sequence, two-formulation and six-period, threesequence, three-formulation designs. Clin Pharmacokinet 2013;52:1033-43

102. Privitera MD, Welty TE, Gidal BE, et al. Generic-togeneric lamotrigine switches in people with epilepsy: the randomised controlled EQUIGEN trial. Lancet Neurol 2016;15:365-72.

103. Srichaiya A, Longchoopol C, Oo-Puthinan S, Sayasathid J, Sripalakit P, Viyoch J. Bioequivalence of generic lamotrigine 100-mg tablets in healthy Thai male volunteers: A randomized, single-dose, two-period, twosequence crossover study. Clin Ther 2008;30:1844-51.

104. Andermann F, Duh MS, Gosselin A, Paradis PE. Compulsory generic switching of antiepileptic drugs: High switchback rates to branded compounds compared with other drug classes. Epilepsia 2007;48:464-9.

105. LeLorier J, Duh MS, Paradis PE, et al. Clinical consequences of generic substitution of lamotrigine for patients with epilepsy. Neurology 2008;70(22 Pt 2):217986.

106. Duh MS, Paradis PE, Latrémouille-Viau D, et al. The risks and costs of multiple-generic substitution of topiramate. Neurology 2009;72:2122-9.

107. Zachry WM 3rd, Doan QD, Clewell JD, Smith BJ. Casecontrol analysis of ambulance, emergency room, or inpatient hospital events for epilepsy and antiepileptic drug formulation changes. Epilepsia 2009;50:493-500.

108. Rascati KL, Richards KM, Johnsrud MT, Mann TA. Effects of antiepileptic drug substitutions on epileptic events requiring acute care. Pharmacotherapy 2009;29:769-74.

109. Labiner DM, Paradis PE, Manjunath R, et al. Generic antiepileptic drugs and associated medical resource utilization in the United States. Neurology 2010;74:156674

110. Gagne JJ, Avorn J, Shrank WH, Schneeweiss S. Refilling and switching of antiepileptic drugs and seizure-related events. Clin Pharmacol Ther 2010;88:347-53.

111. Chaluvadi S, Chiang S, Tran L, Goldsmith CE, Friedman DE. Clinical experience with generic levetiracetam in people with epilepsy. Epilepsia 2011;52:810-5.

112. Perucca E, Albani F, Capovilla G, Bernardina BD, Michelucci R, Zaccara G. Recommendations of the Italian League Against Epilepsy working group on generic products of antiepileptic drugs. Epilepsia 2006;47 Suppl 5:16-20.

113. French Chapter of the International League Against Epilepsy (LFCE): Recommendations on the use of generics for the treatment of epilepsy. Available from: http:// www.ilae.org/visitors/MeetingProceedings/documents/ PRESSRELEASEONGENERICAEDSFRENCHCHAPTER OFTHEILAE_000.pdf. Accessed Mar 2016.

114. American Epilepsy Society. Substitution of different formulations of antiepileptic drugs for the treatment of epilepsy. Available from: https://www.aesnet.org/about_ aes/generic-position-statement. Accessed Mar 2016.

115. Piñeyro-López A, Piñeyro-Garza E, Gómez-Silva M, et al. Bioequivalence of single 100-mg doses of two oral formulations of topiramate: An open-label, randomizedsequence, two-period crossover study in healthy adult male Mexican volunteers. Clin Ther 2009;31:411-7.

116. Cañadillas-Hidalgo FM, Sánchez-Alvarez JC, SerranoCastro PJ, Mercadé-Cerdá JM; en representación de la Sociedad Andaluza de Epilepsia. Consensus clinical practice guidelines of the Andalusian Epilepsy Society on prescribing generic antiepileptic drugs [in Spanish]. Rev Neurol 2009;49:41-7.

117. Yamada M, Welty TE. Generic substitution of antiepileptic drugs: a systematic review of prospective and retrospective 
studies. Ann Pharmacother 2011;45:1406-15.

118. Medicines \& Healthcare products Regulatory Agency. Available from: https://www.gov.uk/government/ organisations/medicines-and-healthcare-productsregulatory-agency. Accessed Mar 2016.
119. NICE guidance CG137. Epilepsies: diagnosis and management. Available from: https://www.nice.org.uk/ guidance/cg137. Accessed Mar 2016.

120. The Medical Council of Hong Kong. Available from: http://www.mchk.org.hk/code.htm. Accessed Mar 2016. 